\title{
Dynamic Contrast-Enhanced Ultrasound Imaging
}

National Cancer Institute

\section{Source}

National Cancer Institute. Dynamic Contrast-Enhanced Ultrasound Imaging. NCI

Thesaurus. Code C116488.

A functional imaging technique that uses the combination of sonography and microbubble contrast agents to render the desired image. 